\title{
The Impact of Away Rotations on the Ophthalmology Residency Match
}

\author{
Hanna L. Tso, BS ${ }^{1}$ Jason Young, MD ${ }^{1} \quad$ Charline S. Boente, MD, MS ${ }^{1} \quad$ Chi Wah Yung, MD ${ }^{1}$ \\ 1 Department of Ophthalmology, Indiana University School of \\ Medicine, Eugene and Marilyn Glick Eye Institute, Indianapolis, \\ Indiana \\ Address for correspondence Chi-Wah Yung, MD, Department of \\ Ophthalmology, Indiana University School of Medicine, Eugene and \\ Marilyn Glick Eye Institute, 1160 W. Michigan Street, Indianapolis IN \\ 46202 (e-mail: ryung@iupui.edu).
}

J Acad Ophthalmol 2021;13:e19-e25.

\begin{abstract}
Background The ophthalmology residency match is highly competitive, and fourthyear medical students frequently complete away rotations at other institutions hoping to increase their chances of matching.

Objective The study aimed to determine the impact of away rotations on the ophthalmology residency selection process and to provide recommendations to faculty for counseling fourth-year medical students as they prepare for the ophthalmology match.

Methods A survey was sent in June 2020 to program directors (PDs), medical student educators (MSEs), and residents at 119 accredited ophthalmology residency programs via the Association of University Professors of Ophthalmology e-mail listserv. The 43 PDs and 38 MSEs who responded were asked questions about their views regarding away rotations and visiting students during the residency selection process. The 83 resident respondents were asked about their interview and match success after completing away rotations. Categorical variables were analyzed by Chi-square test.

Results The majority of PDs and MSEs typically recommend that fourth-year medical students complete away rotations ( $p=0.022$ and $p=0.194$, respectively). The majority believe that an away rotation will increase the chance of the applicant matching with the host institution ( $p=0.004$ and $p=0.001$, respectively). The vast majority of PDs were more likely to offer an interview to a visiting student compared with another equally qualified applicant $(p<0.001)$. However, only one-third of PDs were typically more likely to rank an away rotator higher on their rank list $(p=0.047)$. Two-thirds of residents completed at least one away rotation in medical school (mean $=1.7$ rotations). The majority received interview invitations from at least some of their host institutions $(p<0.001)$. Approximately one-fifth ultimately matched at a host residency program $(p<0.001)$.

Keywords

- medical education

- residency match

- away rotations

- audition electives

Conclusion The majority of ophthalmology PDs and MSEs surveyed recommend that fourth-year medical students complete away rotations and believe that these rotations will increase the chance of the applicant matching at a host institution. The PDs are more likely to offer an interview to a visiting student compared with another equally qualified applicant. For some programs, visiting students may also receive special consideration by being ranked higher on a program's rank list and being more likely to match.
\end{abstract}

received

August 12, 2020

accepted after revision

November 18, 2020
DOI https://doi.org/

10.1055/s-0041-1723849.

ISSN 2475-4757. (c) 2021. The Author(s).

This is an open access article published by Thieme under the terms of the Creative Commons Attribution-NonDerivative-NonCommercial-License, permitting copying and reproduction so long as the original work is given appropriate credit. Contents may not be used for commercial purposes, or adapted, remixed, transformed or built upon. (https://creativecommons.org/ licenses/by-nc-nd/4.0/)

Thieme Medical Publishers, Inc., 333 Seventh Avenue, 18th Floor, New York, NY 10001, USA 
Ophthalmology has become one of the surgical subspecialties with the most competitive residency selection processes. Many fourth-year medical students pursuing ophthalmology seek out additional opportunities to strengthen their applications. Despite the emphasis on strong board exam scores, multiple studies have shown that some of the strongest factors in predicting future success in residency include interpersonal skills, substantial charitable involvement, and personality traits such as agreeableness, cooperation, and self-efficacy. ${ }^{1-5}$ While vital to becoming a successful surgeon, these soft skills are often difficult to discern from the review of an application or even during an interview. ${ }^{3}$ To this end, many fourth-year medical students elect to complete away rotations, or "audition electives," at outside institutions to display their interpersonal skills to potential residency programs. ${ }^{6-15}$

In previous surveys of fourth-year medical students, nearly three-quarters, if not more, of ophthalmology applicants reported auditioning at other institutions. ${ }^{8,11}$ Many applicants complete multiple audition rotations. ${ }^{7,8,11}$ These rotations are beneficial by providing students with novel educational environments and training approaches, opportunities for career exploration, and chances to earn letters of recommendation. ${ }^{9}$ Nonetheless, multiple studies of fourthyear medical students across specialties have found that the primary purposes for students to complete away electives are to find a "good fit" program, make a good impression, and increase the likelihood of interviewing and matching at that program. ${ }^{7,12,13,16}$ Furthermore, given that more than half of ophthalmology applicants match to the same geographic region as their medical school, away rotations may offer applicants an opportunity to signal a geographical preference to residency programs outside of their medical school's region. $^{14,15}$

Despite the emphasis that students place on away rotations, a previous literature review by Lee et al did not support the widespread belief among applicants that away rotations improve the chances of matching at the respective program. ${ }^{17}$ At best, away rotations improved the chance for an interview (i. e., the courtesy interview) but did not improve the chance of matching. As such, a previous survey of ophthalmology resident selection committee members, including program directors (PDs) and chairs, found that less than half of respondents strongly encouraged students to complete away rotations. ${ }^{6}$ In contrast to previous studies, however, the same survey found that over half of the programs were most comfortable ranking and matching applicants with whom they had contact during a rotation. Moreover, over half routinely interview most applicants who do audition electives at their institutions. The reason of this discrepancy exists between the apparent benefits of ophthalmology away rotations and the recommendations given to students is unclear. Furthermore, given that away rotations can place a significant burden on students by being expensive, time consuming, and stressful, fourth-year medical students must consider the cost-benefit analysis of applying to these electives. ${ }^{7-9,11-13,18}$

The role of away rotations in the residency selection process has come under the spotlight this year, especially due to the coronavirus disease 2019 (COVID-19) pandemic resulting in the mass cancellation of away rotations across all specialties nationwide. ${ }^{19,20}$ Conflicting advice and lack of data about the impact of away rotations on the ophthalmology residency match limit the ability of advisors to guide students in making informed decisions. ${ }^{20,21}$ In this study, we sought to elucidate the role of away rotations in the ophthalmology residency selection process and reach conclusions that will aid in the counseling of fourth-year medical students as they prepare for the ophthalmology match.

\section{Methods}

To assess the impact of ophthalmology away rotations, we surveyed PDs, medical student educators (MSEs), and residents at 119 ophthalmology residency programs in June 2020.

\section{Survey Development}

Our survey consisted of three sets of questions corresponding to whether the respondent was a PD, MSE, or resident (for a copy of the survey, see Supplementary Material). The questions for PDs inquired about their typical recommendations to fourth-year medical students regarding away rotations, their tendencies to give advantages during the residency selection process to students who rotated at their institution (i.e., extending automatic or courtesy interviews, ranking an interviewee higher on their rank list), and the match rate for away rotators at their institution. The questions for MSEs asked about their recommendations to students about away rotations and their beliefs regarding whether an away rotation increases the chance of the applicant matching at a host institution. Finally, the questions for residents inquired about the number of away rotations they completed as fourth-year medical students, their interview and match success rate at host institutions, and the financial costs of completing the rotations.

\section{Sample}

We administered the survey to PDs and MSEs at the 119 Accreditation Council for Graduate Medical Education (ACGME) accredited residency programs. Invitations to participate in the study were sent via e-mail through the Association of University Professors of Ophthalmology (AUPO) Data Resource Committee. The resident survey was sent separately to PDs with a request to forward it to residents. The survey was accessible for 2 weeks from June 3, 2020 to June 17, 2020. Reminder e-mails were sent on June 10 and 16. Participation in the survey was voluntary and anonymous.

The Indiana University School of Medicine institutional review board and committees on human subjects granted exempt status for this study.

\section{Data Analysis}

We calculated the response rate for residency programs using 119 as the denominator. Chi-square analysis was used to compare categorical variables. For all analyses, $p<0.05$ was considered statistically significant. 


\section{Results}

\section{Response Rate}

A total of 164 individuals participated in the study: $26.2 \%$ were PDs, $23.2 \%$ were MSEs, and 50.6\% were residents. The PDs and MSEs represented 36.1 and $31.9 \%$, respectively, of the 119 Accreditation Council for Graduate Medical Education accredited residency programs. Assuming that all programs forwarded the resident survey onto their residents, the resident response rate was approximately 5.3\% (83/1566). There was a wide range in the size of the participating programs with 14 (32.6\%) offering two to three residency positions per year, 19 (44.2\%) offering four to five positions, and 10 (23.3\%) offering six or more positions.

\section{Recommendations Given to Applicants}

The majority of PDs typically recommend that fourth-year medical students complete away rotations at other institutions (29; 67.4\%; $p=0.022$; - Table 1). A similar number of PDs believe an away rotation will increase the chance of the applicant matching with that institution $(31 ; 72.1 \% ; p=0.004)$.

A slightly smaller majority of MSEs typically recommend that fourth-year medical students complete away rotations at other institutions $(23 ; 60.5 \% ; p=0.194$; - Table 2). However, a larger percentage of MSEs believe an away rotation will increase the chance of the applicant matching with that institution $(29 ; 76.3 \% ; p=0.001)$.

\section{Prevalence and Cost of Away Rotations}

Approximately, two-thirds of ophthalmology residents completed at least one ( mean $=1.7$, standard deviation $[S D]=0.7$ ) away rotation as a fourth-year medical student (57; 68.7\%; - Table 3). Of those who completed an away rotation, the vast majority believed that the rotation better prepared them for the residency selection process $(50 ; 87.7 \% ; p<0.001)$. Including application costs, room and board, and travel, the total cost of completing audition electives ranged from less than $\$ 1,000$ to $\$ 6,000$ (median range $=\$ 1,000-\$ 2,000$ ).

\section{Interviews}

Less than a quarter of PDs responded that medical students who complete away rotations at their institutions are granted automatic interviews (10; 23.3\%; $p<0.001$; - Table 1). However, the vast majority of PDs responded that a visiting student is more likely to be offered an interview compared with another equally qualified applicant (36; 83.7\%; $p<0.001$ ).

Consistent with these findings, a majority of residents responded that they received interview invitations to some, if not all, of the programs at which they rotated (46; $80.7 \%$; $p<0.001$; - Table 3). The same number of residents believed that doing an away rotation increased their chances of interviewing with an institution (46;80.7\%; $p<0.001)$.

\section{Ranking and Matching}

Approximately, one-third of PDs were more likely to rank an interviewee higher on their rank list if he or she had completed an away rotation at their institution (15; $34.9 \%$;
Table 1 Residency program directors' perspectives on away rotations

\begin{tabular}{|c|c|}
\hline Number of residents per class, $n(\%)$ & \\
\hline 2 & $3(7)$ \\
\hline 3 & $11(25.6)$ \\
\hline 4 & $13(30.2)$ \\
\hline 5 & $6(14)$ \\
\hline 6 & $6(14)$ \\
\hline More than 6 & $4(9.3)$ \\
\hline $\begin{array}{l}\text { Typically recommend that fourth-year medi- } \\
\text { cal students complete away rotations at other } \\
\text { institutions, } n(\%)\end{array}$ & \\
\hline Yes & $29(67.4)$ \\
\hline No & $14(32.6)$ \\
\hline $\begin{array}{l}\text { Believe that an away rotation will increase the } \\
\text { chance of the applicant matching with that } \\
\text { institution, } n(\%)\end{array}$ & \\
\hline Yes & $31(72.1)$ \\
\hline No & $12(27.9)$ \\
\hline $\begin{array}{l}\text { Medical students who complete an away } \\
\text { rotation at your institution granted auto- } \\
\text { matic interviews, } n(\%)\end{array}$ & \\
\hline Yes & $10(23.3)$ \\
\hline No & $33(76.7)$ \\
\hline $\begin{array}{l}\text { Medical students who complete an away } \\
\text { rotation at your institution more likely to be } \\
\text { offered an interview compared with another } \\
\text { equally qualified applicant, } n(\%)\end{array}$ & \\
\hline Yes & $36(83.7)$ \\
\hline No & $7(16.3)$ \\
\hline $\begin{array}{l}\text { More likely to rank an interviewee higher on } \\
\text { your rank list if they have completed an away } \\
\text { rotation at your institution, } n(\%)\end{array}$ & \\
\hline Yes & $15(34.9)$ \\
\hline No & $28(65.1)$ \\
\hline $\begin{array}{l}\text { Percentage of medical students in the past } \\
5 \text { years who completed an away rotation at } \\
\text { your institution who ultimately matched with } \\
\text { your program, } n(\%)\end{array}$ & \\
\hline $0-25 \%$ & $33(76.7)$ \\
\hline $26-50 \%$ & 9 (20.9) \\
\hline $51-75 \%$ & $1(2.3)$ \\
\hline
\end{tabular}

$p=0.047 ;$ - Table 1). One-fifth of PDs reported a matching rate of 26 to $50 \%$ for students who completed away rotations with their institutions in the past 5 years $(9 ; 20.9 \%)$. However, the majority of PDs reported that only a quarter or less of visiting medical students ultimately matched with their program (33; 76.7\%). Consistent with the majority PD response, approximately one-fifth of resident respondents ultimately matched at an institution where they did an away rotation $(11 ; 19.3 \%$; $p<0.001$; - Table 3). 
Table 2 Medical student educators' perspectives on away rotations

\begin{tabular}{|c|c|}
\hline $\begin{array}{l}\text { Typically recommend that fourth year } \\
\text { medical students complete away rotations } \\
\text { at other institutions, } n(\%)\end{array}$ & \\
\hline Yes & $23(60.5)$ \\
\hline No & $15(39.5)$ \\
\hline $\begin{array}{l}\text { Believe that an away rotation will increase } \\
\text { the chance of the applicant matching } \\
\text { with that institution, } n(\%)\end{array}$ & $29(76.3)$ \\
\hline Yes & $9(23.7)$ \\
\hline No & \\
\hline
\end{tabular}

Table 3 Residents' perspectives on away rotations

\begin{tabular}{|c|c|}
\hline $\begin{array}{l}\text { Completed an away rotation as a } \\
\text { fourth-year medical student, } n(\%)\end{array}$ & \\
\hline Yes & $57(68.7)$ \\
\hline No & $26(31.3)$ \\
\hline \multicolumn{2}{|l|}{$\begin{array}{l}\text { Number of away rotations } \\
\text { completed, } n(\%)\end{array}$} \\
\hline 1 & $27(47.4)$ \\
\hline 2 & $22(38.6)$ \\
\hline 3 & $8(14.0)$ \\
\hline \multicolumn{2}{|l|}{$\begin{array}{l}\text { Received an interview invitation } \\
\text { to the programs at which } \\
\text { you rotated, } n(\%)\end{array}$} \\
\hline Yes, all of them & 33 (57.9) \\
\hline Yes, some of them & $13(22.8)$ \\
\hline No, none of them & $11(19.3)$ \\
\hline \multicolumn{2}{|l|}{$\begin{array}{l}\text { Believe completing an away rotation } \\
\text { prepared you for the residency } \\
\text { selection process, } n(\%)\end{array}$} \\
\hline Yes & $50(87.7)$ \\
\hline No & $7(12.3)$ \\
\hline \multicolumn{2}{|l|}{$\begin{array}{l}\text { Believe doing an away rotation } \\
\text { increased your chances of interviewing } \\
\text { with that institution, } n(\%)\end{array}$} \\
\hline Yes & 46 (80.7) \\
\hline No & $11(19.3)$ \\
\hline \multicolumn{2}{|l|}{$\begin{array}{l}\text { Matched at host program after } \\
\text { away rotation, } n(\%)\end{array}$} \\
\hline Yes & $11(19.3)$ \\
\hline No & $46(80.7)$ \\
\hline \multicolumn{2}{|l|}{ Cost of completing away rotations, $n(\%)$} \\
\hline$<\$ 1,000$ & $20(35.1)$ \\
\hline$\$ 1,000-\$ 2,000$ & $16(28.1)$ \\
\hline$\$ 2,001-\$ 3,000$ & $12(21.1)$ \\
\hline$\$ 3,001-\$ 4,000$ & $2(3.5)$ \\
\hline$\$ 4,001-\$ 5,000$ & $5(8.8)$ \\
\hline$\$ 5,001-\$ 6,000$ & $2(3.5)$ \\
\hline
\end{tabular}

\section{Discussion}

This study found that away rotations are prevalent among ophthalmology applicants, as over two-thirds of resident respondents participated in at least one away rotation as a fourth-year medical student (mean $=1.7, \mathrm{SD}=0.7$ ). Previous studies have reported that fourth-year medical students across specialties complete a mean of 1.8 audition electives and that ophthalmology-specific applicants complete a mean of 1.9. ${ }^{7,8}$ Given the pervasiveness of away rotations, the present study aimed to elucidate the advantages given to away rotators during the ophthalmology residency selection process.

In our survey of PDs, $83.7 \%$ reported that they were more likely to offer an interview to a visiting medical student who had completed an away rotation at their institution compared with another equally qualified applicant. A previous study reported that $51.6 \%$ of programs routinely interview most applicants who do audition electives at their institutions, and that $58 \%$ of programs are most comfortable ranking and matching applicants with whom they have contact during a rotation. ${ }^{6}$ Our findings demonstrate a more prominent advantage for away rotators at the interview invitation phase than previously reported. Furthermore, our study is the first to examine the practice of extending automatic, or courtesy, interviews to away rotators. Of the PDs surveyed, 23.3\% reported granting automatic interviews to visiting students.

In our survey of residents, as fourth-year medical students $57.9 \%$ received interviews from all of their host institutions, $22.8 \%$ received interviews from some of them, and $19.3 \%$ received interviews from none. Cumulatively, $80.7 \%$ received interviews from at least one of their host institutions. Thus, away rotations play an important role in substantially increasing the likelihood that a student will receive an interview invitation from the host program.

After the interview stage, only one-third of PDs were more likely to rank an interviewee higher on their rank list if he or she had completed an away rotation at their institution. Thus, while away rotations can still improve a program's ranking of an applicant in some cases, this advantage is less pronounced than that of receiving the initial interview offer. One-fifth of PDs reported a matching rate of 26 to $50 \%$ for students who completed away rotations with their institutions in the past 5 years. One program even reported a match rate of 51 to $75 \%$ for away rotators. However, the majority of PDs reported that only a quarter or less of away rotators ultimately matched with their program. In line with these findings, approximately one-fifth of resident respondents ultimately matched at a host institution. This percentage of successful matches is lower than a previously reported match rate of $32 \%$ for ophthalmology visiting students. ${ }^{8}$

Therefore, the greatest advantage conferred to away rotators appears to be at the interview selection stage, with smaller positive effects at the ranking and matching stages. This finding is consistent with that suggested by Lee et al. ${ }^{17}$ After an interview invitation is extended, other factors likely supersede a prior audition elective in importance (e.g., interview performance, a "good fit" with the program). Additionally, the 
advantages are not uniform across programs, as some heavily favor away rotators by extending automatic interviews or routinely ranking them higher. From the applicant's perspective, the majority of residents responded that completing an away rotation better prepared them for the residency selection process. Thus, away rotations can also provide intangible benefits to fourth-year medical students, including an opportunity to discover what they value most in a residency by assessing a program structured differently from their home institution.

Regarding recommendations given to applicants, our study found that $67.4 \%$ of PDs typically recommend that fourth-year medical students complete away rotations at other institutions, and $72.1 \%$ believe an away rotation will increase the chance of the applicant matching with that institution. Of the MSEs surveyed, 60.5\% typically recommend away rotations, and $76.3 \%$ believe an away rotation will increase the chance of matching. Given the aforementioned advantages to away rotators, it is unsurprising that the majority of PDs and MSEs recommend that students audition at other programs. In fact, the recommendation rates in our survey are higher than those previously reported. In a prior survey of 65 ophthalmology residency selection committee members, including PDs and chairs, only $40 \%$ of respondents reported strongly encouraging students to complete audition electives and $46.7 \%$ reported doing so only in special circumstances (e.g., geographic restrictions for matching). ${ }^{6}$

The same survey, published in 2010, indicated that "there is a generally agreed-on policy among residency directors to discourage excessive audition electives." ${ }^{6}$ Our findings in 2020, which demonstrate a much larger role for away rotations in today's residency selection process, reflect a shift in opinion among PD's over the last decade. Perhaps as ophthalmology becomes an increasingly competitive specialty with regards to the residency match, more PD's and faculty are advising students to pursue away rotations. Indeed, the past decade has seen a nearly 10-point rise in the average United States Medical Licensing Examination (USMLE) step 1 score of ophthalmology residency applicants. $^{22,23}$ Subsequently, the role of away rotations may have increased in importance for students wishing to further distinguish themselves and for residency programs seeking to evaluate applicants based on noncognitive metrics.

Regarding a discrepancy in recommendations among programs, Nallasamy et al found that only $23.1 \%$ of respondents from the largest programs encouraged students to complete audition electives, and $61.5 \%$ encouraged them only in special circumstances. ${ }^{6}$ The reason of respondents from larger programs are less likely to encourage audition electives is unclear. Perhaps those from larger programs believe that they have more residency positions to offer to their home medical students. Or perhaps they believe their program is strong enough that home students need not look elsewhere for excellent training.

Despite fewer MSEs recommending away rotations to students compared with PDs, more MSEs actually believe an away rotation will enhance the likelihood of matching. One possible explanation for this discrepancy is a greater awareness among MSEs of the costs and burdens that students face to complete away rotations. Our survey found that the cost of completing ophthalmology audition electives ranged from less than $\$ 1,000$ to $\$ 6,000$ (median range $=\$ 1,000-\$ 2,000)$. Previous surveys of fourth-year medical students have reported a range of $\$ 500$ to $\$ 4,000 .^{7,8,11}$ In addition, students frequently cited cost as the reason they did not participate in more or any audition electives. ${ }^{7,11}$ Although the costs of away rotations pale beside the total cost of medical school, they still represent a significant investment for students already heavily in debt.

Beyond the financial burden, the application process for away rotations is unstandardized, with different schools setting different application deadlines and operating on different academic calendars. ${ }^{9,24}$ Furthermore, the away rotation itself can be a highly stressful experience. Though students seek to leave a good impression on programs, and in some cases, earn letters of recommendations, a negative evaluation of the student can hurt his or her chances of matching with that program. Therefore, students accept some inherent risk by participating in away electives, which can feel like "month-long interviews." ${ }^{15}$ Finally, our study found that $19.3 \%$ of resident respondents ultimately matched at an institution where they completed an away rotation during medical school. Thus, the majority of students do not ultimately match at a host program, despite the significant investment required to audition. Given the financial, logistical, and personal challenges of enrolling in away rotations, fourth-year medical students must consider the cost-benefit analysis of applying to these electives. The MSEs who are more likely than PDs to interact frequently with students may be more cognizant of these burdens and less routinely encourage students to audition.

This study has several limitations. First, the match rate for away rotators at a host institution was determined by surveying current ophthalmology residents. We did not survey fourthyear medical students immediately following their residency match. Because we only surveyed those who successfully matched into ophthalmology, our finding that $19.3 \%$ of residents matched at a program where they rotated is likely an overestimate for visiting medical students at large. Selection bias may have further skewed the results in favor of away rotations if respondents with more positive views of these rotations were more likely to participate in the survey. Moreover, residents who did not have a home ophthalmology department in medical school may have been more likely to match at a program where they completed an away rotation.

In addition, several factors may have reduced the response rate of the survey. Namely, the survey was distributed by the AUPO Data Resource Committee in June 2020. In addition to June being a relatively busy month in education, the COVID-19 pandemic added unprecedented burdens to residency programs nationwide, potentially limiting the number of survey responses. The seven-question survey itself was relatively short and straightforward.

Another consideration is that the responses by PDs and MSEs may have been skewed during a pandemic when the vast majority of away rotations were cancelled in 2020. As 
residency programs felt the absence of visiting students, respondents may have overvalued the weight of away rotations and overestimated the advantages conferred by these electives. Because the initial survey was submitted to the AUPO in January 2020 prior to the arrival of COVID-19 in the United States, specific survey questions addressing the impact of COVID-19 on recommendations for away rotations were not included.

Furthermore, our survey of PDs and MSEs was subjective in nature. For example, questions centered around whether they typically recommend that students complete away rotations and if they routinely interview away rotators, but the frequencies of these recommendations or interview practices were not quantified.

Additionally, our study did not investigate the complex reasons for why some away rotators receive interviews from their host programs while others do not. Possible explanations for not receiving an interview include lackluster clinical performance during the rotation, inadequate time to interact with residency selection committee members, or weaknesses in the student's application (i.e., low board scores or grades). Another possibility is that students who auditioned ranked programs lower due to unfavorable information they learned while on the rotation, referred to as the "dirty laundry effect."11

Finally, our study did not take geography into account. It is unclear if the advantages for visiting students described in this study are more pronounced in certain geographic regions of the United States or if individual programs tend to have their own unique policies. As away rotations can signal applicants' geographical preferences for residency, future studies could delineate the impact of away rotations on programs in geographically proximate and disparate regions as the host program. For example, would an applicant from the Midwest who auditions at a program on the West Coast be more likely to receive interviews from other West Coast programs, in addition to the host program? Would he or she be less likely to receive interviews from programs on the East Coast or in the South due to not auditioning and expressing interest in those geographical areas?

The significance of ophthalmology away rotations has become more relevant than ever during this year's application cycle in which the vast majority of away rotations nationwide have been cancelled due to the COVID-19 pandemic. ${ }^{19,20}$ Virtually, all fourth-year medical students are unable to complete away rotations in 2020 , save those who do not have a home ophthalmology department and would otherwise lack exposure to the field, or those for whom an away rotation is required for graduation or accreditation requirements. The 2021 ophthalmology match results may shed light on the importance of away rotations due to their unavailability this year. A potential consequence is that residency programs may favor their home medical students with whom they are more familiar over outside students, given their inability to meet and interact with away rotators.

Interestingly, some residency programs across specialties are offering "virtual away rotations" or "virtual open houses" as substitutes for traditional away rotations. ${ }^{25-28}$ These "virtual away rotations" may include month-long virtual lectures by the host institution's faculty, virtual case discussions, research opportunities, and chances to speak with current residents to better understand the residency program. "Virtual open houses" are another avenue for programs to promote themselves to prospective students and can include presentations by the PD, chair, and current residents. ${ }^{25}$ However, the value of these virtual opportunities remains to be seen, as students are unable to see patients and demonstrate their clinical and interpersonal skills to the host programs. Nonetheless, the monumental effort on the part of these programs to develop alternative "audition" opportunities further emphasizes the value they place on traditional away rotations to meet visiting students ahead of the application season.

In summary, our study suggests that fourth-year medical students who complete away rotations have a substantial advantage during the ophthalmology residency selection process at the interview selection stage. Away rotators are significantly more likely to receive interview invitations from their host institutions compared with other equally qualified applicants. For some programs, they may also receive special consideration by being ranked higher on a program's rank list and being more likely to match. However, advantages at these later stages in the application process are less pronounced than that at the initial interview invitation stage. Despite the apparent benefits of away rotations, many applicants successfully match into ophthalmology residency each year without having auditioned anywhere. Nonetheless, the increasing competitiveness of the ophthalmology residency selection process is reason enough for many students to go above and beyond to secure a residency position. We hope our findings will assist ophthalmology faculty and advisors in guiding fourth-year medical students, and ultimately allow students to make more informed decisions about pursuing away rotations as they prepare for the ophthalmology match.

\section{Funding}

None.

Conflict of Interest

None declared.

\section{Acknowledgments}

The authors wish to thank the Association of University Professors of Ophthalmology for their assistance in distributing the survey to the ACGME-accredited ophthalmology residency programs.

\section{References}

1 Valley B, Camp C, Grawe B. Non-cognitive factors predicting success in orthopedic surgery residency. Orthop Rev (Pavia) 2018;10(03):7559

2 Spitzer AB, Gage MJ, Looze CA, Walsh M, Zuckerman JD, Egol KA. Factors associated with successful performance in an orthopaedic surgery residency. J Bone Joint Surg Am 2009;91(11): 2750-2755

3 Bell RM, Fann SA, Morrison JE, Lisk JR. Determining personal talents and behavioral styles of applicants to surgical training: a new look at an old problem, part II. J Surg Educ 2012;69(01):23-29 
4 Merlo LJ, Matveevskii AS. Personality testing may improve resident selection in anesthesiology programs. Med Teach 2009;31 (12):e551-e554

5 Phillips D, Egol KA, Maculatis MC, et al. Personality factors associated with resident performance: results from 12 Accreditation Council for Graduate Medical Education accredited orthopaedic surgery programs. J Surg Educ 2018;75(01):122-131

6 Nallasamy S, Uhler T, Nallasamy N, Tapino PJ, Volpe NJ. Ophthalmology resident selection: current trends in selection criteria and improving the process. Ophthalmology 2010;117(05):1041-1047

7 Benson NM, Stickle TR, Raszka WV Jr. Going "fourth" from medical school: fourth-year medical students' perspectives on the fourth year of medical school. Acad Med 2015;90(10):1386-1393

8 Winterton M, Ahn J, Bernstein J. The prevalence and cost of medical student visiting rotations. BMC Med Educ 2016;16(01):291

9 Griffith M, DeMasi SC, McGrath AJ, Love JN, Moll J, Santen SA. Time to reevaluate the away rotation: improving return on investment for students and schools. Acad Med 2019;94(04):496-500

10 Andrews MA, Paolino ND, DeZee KJ, Hemann B. Perspective of the graduating medical student: the ideal curriculum for the fourth year of undergraduate medical education. Mil Med 2016;181(11): e1455-e1463

11 Higgins E, Newman L, Halligan K, Miller M, Schwab S, Kosowicz L. Do audition electives impact match success? Med Educ Online 2016;21:31325

12 O'Donnell SW, Drolet BC, Brower JP, LaPorte D, Eberson CP. Orthopaedic surgery residency: perspectives of applicants and program directors on medical student away rotations. J Am Acad Orthop Surg 2017;25(01):61-68

13 Drolet BC, Brower JP, Lifchez SD, Janis JE, Liu PY. Away rotations and matching in integrated plastic surgery residency: applicant and program director perspectives. Plast Reconstr Surg 2016;137 (04):1337-1343

14 Loh AR, Joseph D, Keenan JD, Lietman TM, Naseri A. Predictors of matching in an ophthalmology residency program. Ophthalmology 2013;120(04):865-870

15 Lufty-Clayton L, Morrissey T, Pelletier-Bui A, et al.The emergency medicine applying guide. Council of Emergency Medicine Residency Directors. 2018. Accessed July 23, 2020 at: https://www. cordem.org/globalassets/files/committees/student-advising/ 2018-applying-guide-cord-cdem-emra-rsa.docx.pdf

16 Mueller PS, McConahey LL, Orvidas LJ, et al. Visiting medical student elective and clerkship programs: a survey of US and Puerto Rico allopathic medical schools. BMC Med Educ 2010; $10: 41$
17 Lee AG, Golnik KC, Oetting TA, et al. Re-engineering the resident applicant selection process in ophthalmology: a literature review and recommendations for improvement. Surv Ophthalmol 2008; 53(02):164-176

18 Venincasa MJ, Cai LZ, Gedde SJ, Uhler T, Sridhar J. Current applicant perceptions of the ophthalmology residency match. JAMA Ophthalmol 2020;138(05):460-466

19 The Coalition for Physician Accountability's Work Group on Medical Students in the Class of 2021 Moving Across Institutions for Post Graduate Training. Final report and recommendations for medical education institutions of LCME-accredited, U.S. osteopathic, and non-U.S. medical school applicants. 2020. Accessed July 23, 2020 at: https://acgme.org/Portals/0/PDFs/ReportMovingAcrossInstitutions.pdf

20 Quillen DA, Siatkowski RM, Feldon Sof the Association of University Professors of Ophthalmology. COVID-19 and the ophthalmology match. Ophthalmology 2020:S0161-6420(20)30641-2

21 Grubbs JR Jr, Mian SI. Advising students interested in ophthalmology: a summary of the evidence. Ophthalmology 2016;123 (07):1406-1410

22 Association of University Professors of Ophthalmology SF Match. 2020 Ophthalmology residency match summary report. Accessed October 28, 2020 at: https://sfmatch.org/PDFFilesDisplay/Ophthalmology_Residency_Stats_2020.pdf

23 Association of University Professors of Ophthalmology SF Match. 2019 Ophthalmology residency match summary report. Accessed October 28, 2020 at: https://sfmatch.org/PDFFilesDisplay/Ophthalmology_Residency_Stats_2019.pdf

24 Association of American Medical Colleges. Visiting student learning opportunities. Accessed July 23, 2020 at: https://www. aamc.org/students/medstudents/vsas

25 Johns Hopkins School of Medicine. Visiting medical students: application process. Accessed July 23, 2020 at: https://www. hopkinsmedicine.org/som/VisMedStd

26 University of Arkansas for Medical Sciences. Virtual visiting student rotation program. Accessed July 23, 2020 at: https://ortho.uams. edu/medical-students/visiting-medical-student-rotation

27 NYU Langone Health Department of Ophthalmology. Visiting medical students: summer 2020 virtual education series for applying medical students. Accessed July 23, 2020 at: https:// med.nyu.edu/ophthalmology/education/medical-student-training/visiting-medical-students

28 The New York Eye and Ear Infirmary of Mount Sinai. A virtual open house series for ophthalmology residency applicants. Accessed 2020 at: https://www.nyee.edu/education/ophthalmology-residency 